\title{
TRACE ELEMENTS IN THE SOILS OF THE TIKVES REGION
}

\author{
Boev B. ${ }^{1}$ \\ ${ }^{1}$ Faculty of Mining and Geology Stip; University St. Siryl and Methodius Skopje, Goce Delcev 89, \\ 2000 Stip; e-mail: bboev@rgf.ukum.edu.mk
}

\begin{abstract}
The paper presents the results obtained during the investigations carried out for the availability of trace elements $(\mathrm{Ni}, \mathrm{Cd}, \mathrm{Cr}, \mathrm{B})$ to the soils of the Tikves region. Examination by ICP-AES method were carried out on fifty samples taken in the vicinity of the villages of Begniste, Resava, Vozarci, Drenovo, Sirkovo, Manastirec, Sivec, Rosoman, Sopot, Vatasa, Kavadarci, the Beli Kamenja site as well as a number of samples collected between the places. The results obtained indicate high selenium quantities in the vicinity of Rosoman. Increased nickel concentrations, cadmium and boron along the Crna River course were also determined.
\end{abstract}

Key words: arsenic, thallium, trace elements.

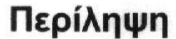

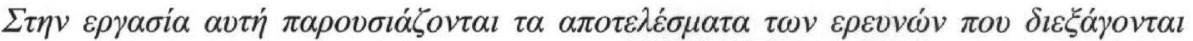

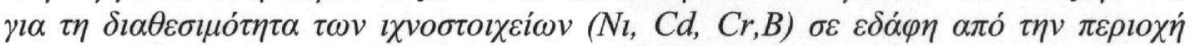

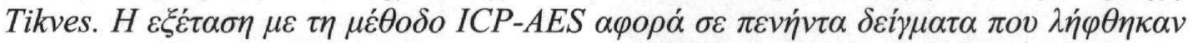

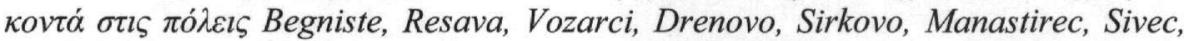

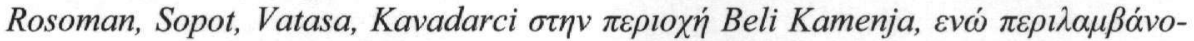

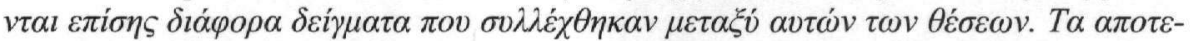

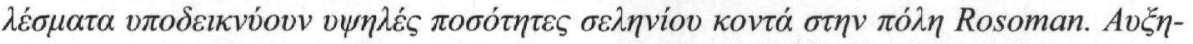

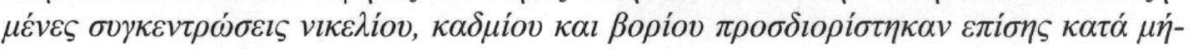

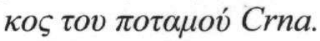

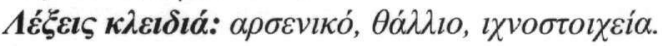

\section{Introduction}

The region of Tikves occupies the middle parts of the River Vardar valley. It includes the municipalities of Rosoman, Kavadraci, Negotino and Demir Kapija. The climate and soil in the region are favourable for viticulture and growing of vegetables. Most of the arable land is irrigated using the water of Lake Tikves. Annual production of grapes for making wine exceeds 100 million tons and those for eating 10 million tons. In that regard, investigations on the composition of the soil and the concentration of trace elements are of particular importance.

\section{Geology of the terrain}

The Tikves area occupies the central parts of the Vardar zone. It is one of the largest geotectonic units in the Republic of Macedonia. The geology consists of rocks of various lithological composition and stratigraphy-from Paleozoic-Mesozoic to Quaternary formations. Igneous, 
sedimentary and metamorphic rocks have been determined. Igneous rocks have been found as an ophiolite series and as volcanic rocks. Sedimentary rocks are present as limestones, gravels, conglomerates, sands, sandstones, clays, whereas metamorphic rocks are present as marbles, quartzites, schists (Fig. 1). The complex geological structure implies that the area consists of diverse soil types.
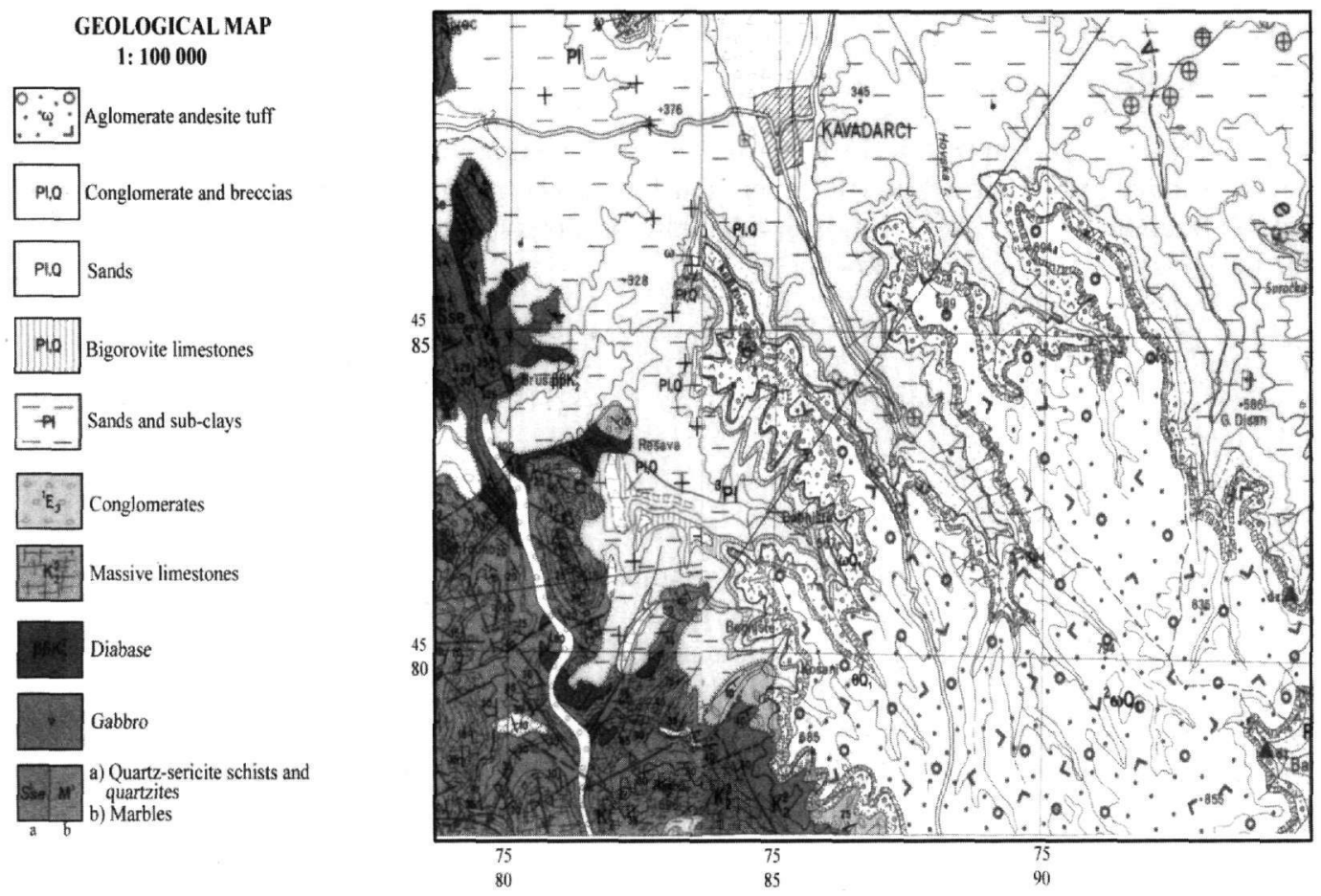

Figure 1 - Geological map of the Tikvesh region

\section{Types of soils in the Tikves region}

Examinations carried out so far have determined the following types of soils (Table 1).

Table 1 - Types of soils in the Tikves region

\begin{tabular}{|l|r|}
\hline Type of soil & in \% \\
\hline Alluvial eroded carbonate soils & 44.41 \\
\hline Inundated alluvium & 14.80 \\
\hline Chernozems & 7.69 \\
\hline Brown carbonate & 6.50 \\
\hline Carbonate deluvial & 5.91 \\
\hline Eroded chernozems & 5.22 \\
\hline Alluvial carbonate & 4.82 \\
\hline Dark clays & 4.64 \\
\hline Degraded chernozems & 3.97 \\
\hline Other soil types & 2.04 \\
\hline
\end{tabular}


The most common type is alluvial eroded carbonate soil overlying the slopes used mostly for viticulture. The inundated alluvium, alluvial carbonate soils can be found along the Crna and Luda Mara River courses and are used for vegetable growing, orchards and vineyards.

Chernozems, eroded and degraded chernozems can be seen on the flat and slope parts. The soils are used for vegetable growing, orchards, viticulture, forage crops and wheat growing.

\section{Methods of work}

Soil samples are dried in the air, or in an oven at a temperature not exceeding 40.C. If necessary, the soil sample is crushed while still damp and friable and again after drying. The soil is sieved and the fraction smaller than $2 \mathrm{~mm}$ is divided into portions mechanically or by hand for analysis. The necessary procedures are following.

\subsubsection{Mixing}

A series of 5 samples taken from 1 grid, coded as $-\mathrm{C},-\mathrm{N},-\mathrm{E},-\mathrm{W},-\mathrm{S}$, are mix well and measured in order to represent the grid.

\subsubsection{Drying}

Samples are dried completely in air or in a ventilated drying oven from which the moist air has been removed. Dry until the loss in mass of the soil sample is not greater than $5 \%$ per $24 \mathrm{~h}$. To accelerate the drying process, break down the size of larger clods (greater than $15 \mathrm{~mm}$ ) during the process. When samples are dried in air, crush them lightly by hand using a wooden hammer or a mortar and pestle. When samples are dried in an oven, remove them temporarily from the oven and treat them in the same way. This procedure also makes it easier to separate the particles greater than $2 \mathrm{~mm}$.

\subsubsection{Crushing and removal of coarse materials}

If soil samples have dried into clods, crushing is necessary. Before crushing, remove stones, fragments of glass and rubbish etc., which are larger than $2 \mathrm{~mm}$ by sieving and hand picking. Take care to minimize the amount of fine material adhering to the separated stones, etc. Crush the dried soil into particles no larger than $2 \mathrm{~mm}$ using suitable apparatus.

\subsubsection{Sieving}

Sieve the dried and crushed sample by hand or using a mechanical shaker. Remove stones and fresh plant fragments, glass, etc. from the fraction remaining on the sieve. Crush any clods left behind on the sieve separately and return them to the sample.

\subsection{5. (Milling)}

If a test sample of less than $2 \mathrm{~g}$ is to be taken for the analysis, it is essential to further comminute the fraction less than $2 \mathrm{~mm}$. Mill a representative subsample of the dried and sieved soil until the complete subsamples just passes through a sieve of $250 \mu \mathrm{m}$ or a size specified. If more than one analysis is to be made, sufficient material should be ground to the smallest particle size specified to enable all the analyses to be made on this one subsample.

\subsubsection{Pretreatment for digestion}

The milled sample (approx. $0.5 \mathrm{~g}$ ) is weighed, then transferred to an evaporating dish and $5 \mathrm{ml}$ of nitric acid is added. The dish is placed on the hot plate at $150{ }^{\circ} \mathrm{C}$ and evaporated until approximately $1 \mathrm{ml}$ of nitric acid remains. Note that several successive additions of nitric acid may be 
necessary until the emission of nitrous vapors ceases to remove all the organic matter. In such cases, the dish is removed from the hot plate and cooled to room temperature before adding the next portion of nitric acid.

\subsubsection{Digestion}

$5 \mathrm{ml}$ of hydrofluoric acid and 1,5 $\mathrm{ml}$ of perchloric acid are added to the pretreated test portion in the PTFE beaker or the platinum crucible. The mixture is heated on the hot plate until the dense fumes of perchloric acid and silicon tetrafluoride cease. The mixture cannot be allowed to evaporate completely. The beaker is removed from the hot plate, allowed to cool, then $1 \mathrm{ml}$ of hydrochloric acid or $1 \mathrm{ml}$ of nitric acid and approximately $5 \mathrm{ml}$ of water are added to dissolve the residue. The beaker is warmed briefly on the hot plate to assist dissolution. Transfer this solution to the $50 \mathrm{ml}$ volumetric flask, fill to the mark and mix well. A solid phase remaining in the resultant solution indicates incomplete dissolution.

\subsubsection{ICP method}

An ICP source consists of a flowing stream of argon gas ionized by an applied radio frequency field typically oscillating at $27.1 \mathrm{MHz}$. This field is inductively coupled to the ionized gas by a water-cooled coil surrounding a quartz "torch" that supports and confines the plasma. A sample aerosol is generated in an appropriate nebulizer and spray chamber and is carried into the plasma through an injector tube located within the torch. The sample aerosol is injected directly into the ICP, subjecting the constituent atoms to temperatures of about 6000 to $8000{ }^{\circ} \mathrm{K}$. Because this results in almost complete dissociation of molecules, significant reduction in chemical interferences is achieved. The high temperature of the plasma excites atomic emission efficiently. Ionization of a high percentage of atoms produces ionic emission spectra. The ICP provides an optically "thin" source that is not subject to self-absorption except at very high concentrations. Thus linear dynamic ranges of four to six orders of magnitude are observed for many elements. The efficient excitation provided by the ICP results in low detection limits for many elements. This, coupled with the extended dynamic range, permits effective multielement determination of metals. The light emitted from the ICP is focused onto the entrance slit of either a monochromator or a polychromator that effects dispersion. A precisely aligned exit slit is used to isolate a portion of the emission spectrum for intensity measurement using a photomultiplier tube. The monochromator uses a single exit slit/photomultiplier and may use a computer-controlled scanning mechanism to examine emission wavelengths sequentially. The polychromator uses multiple fixed exit slits and corresponding photomultiplier tubes; it simultaneously monitors all configured wavelengths using a computer-controlled readout system. The sequential approach provides greater wavelength selection while the simultaneous approach can provide greater sample throughput.

\section{Results and discussion}

The results obtained during the examinations are given in Table 2. It can be seen from Table 2 that the mean Se value in soils ranges within $1.7 \mathrm{ppm}$ (from 1.10 to 6.30). The highest Se value was found near the village of Sopot (5 to $6.30 \mathrm{ppm}$ ). The map of distribution also shows that significant anomalies occur in the region of Sirkovo and Rosoman.

The results show that the soils in the Tikves region contain elevated selenium contents compared with those in the (0.14-0.94 ppm) (Ure at al. 1979, Frank et al. 1979, Lag 1974, Steinnes 1980). The increased amounts are due to the combustion of fossil fuels in the FENI processing plants in the vicinity of Vozarci. It is of note that the increased amounts of selenium are due to the dry climate that enhances the increase of selenium in the soil and the use of fertilizers in vineyards.

Investigations carried out for the presence of nickel indicate that its mean value in the soils of the Tikves region is $83.2 \mathrm{ppm}$ (from 27 to $195 \mathrm{ppm}$ ). A comparison with the values found in some countries in the world (mean value from 4 to $50 \mathrm{ppm}$ ) indicates that in the area of Sirkovo and 
Rosoman there are increased contents of nickel (Fig. 2) (Bradley 1980, Aubert et al. 1977, McKeague et al. 1974, Tjell et al. 1972). The increased contents of nickel are similar to the values published for some region in the world in which contamination comes from local sources, mostly industry (mainly non-ferrous industries, iron, steel and chemical industries), agriculture, use of mineral fertilizers, especially phosphates, road traffic etc. (Cox et al. 1981).

The results show that the soils in the Tikves region contain thallium in the ranges between 0.02 $0.08 \mathrm{ppm}$. Arsenic concentrations in soils of the Tikves region are in the interval 0.5-1.5 ppm.

Table 2 - Concentration of As, Tl, Se, Ni, Cr, Cd, B in soils of the Tikves region (ppm)

\begin{tabular}{|c|c|c|c|c|c|c|c|c|c|c|}
\hline & \multicolumn{3}{|c|}{ Coordinates } & \multicolumn{7}{|c|}{ Concentration } \\
\hline & $\boldsymbol{x}$ & $\boldsymbol{y}$ & $\mathbf{z}$ & $\begin{array}{c}\text { Ni } \\
(p p m)\end{array}$ & $\begin{array}{c}\text { Cr } \\
(p p m)\end{array}$ & $\begin{array}{c}\text { Cd } \\
(\text { ppm })\end{array}$ & $\begin{array}{c}\text { B } \\
(p p m)\end{array}$ & $\begin{array}{c}\text { Se } \\
(p p m)\end{array}$ & $\begin{array}{c}\text { As } \\
(p p m)\end{array}$ & $\begin{array}{c}\mathbf{T I} \\
(p p m)\end{array}$ \\
\hline 1 & 458000 & 758200 & 320 & 77 & 108 & 3.61 & 41 & 1.50 & 0.5 & 0.02 \\
\hline 2 & 458000 & 784000 & 400 & 79 & 106 & 3.25 & 40 & 1.30 & 0.7 & 0.03 \\
\hline 3 & 458200 & 758200 & 400 & 80 & 102 & 4.61 & 45 & 1.60 & 0.6 & 0.01 \\
\hline 4 & 458200 & 758400 & 400 & 85 & 115 & 4.50 & 42 & 1.30 & 1.30 & 0.04 \\
\hline 5 & 458200 & 758600 & 500 & 88 & 110 & 4.20 & 41 & 1.50 & 1.2 & 0.02 \\
\hline 6 & 458400 & 758000 & 230 & 78 & 100 & 4.10 & 45 & 1.20 & 1.1 & 0.05 \\
\hline 7 & 458400 & 758200 & 250 & 80 & 110 & 3.90 & 38 & 1.30 & 0.9 & 0.03 \\
\hline 8 & 458400 & 758400 & 300 & 85 & 105 & 4.50 & 41 & 1.20 & 1.0 & 0.06 \\
\hline 9 & 458600 & 758000 & 280 & 80 & 92 & 5.34 & 45 & 1.40 & 1.2 & 0.07 \\
\hline 10 & 458600 & 758200 & 270 & 85 & 98 & 5.50 & 46 & 1.10 & 0.8 & 0.08 \\
\hline 11 & 458600 & 758600 & 400 & 60 & 70 & 3.5 & 31 & 1.10 & 0.7 & 0.05 \\
\hline 12 & 458700 & 757880 & 380 & 85 & 93 & 4.41 & 45 & 1.30 & 0.8 & 0.06 \\
\hline 13 & 458700 & 758000 & 270 & 84 & 98 & 4.50 & 46 & 1.20 & 0.8 & 0.04 \\
\hline 14 & 458700 & 758200 & 290 & 83 & 100 & 4.30 & 41 & 1.30 & 0.5 & 0.08 \\
\hline 15 & 458700 & 758400 & 260 & 67 & 51 & 4.87 & 31 & 1.50 & 0.6 & 0.05 \\
\hline 16 & 458700 & 758600 & 260 & 65 & 50 & 4.60 & 30 & 1.30 & 0.4 & 0.04 \\
\hline 17 & 458700 & 758800 & 560 & 40 & 45 & 3.70 & 30 & 1.20 & 0.6 & 0.06 \\
\hline 18 & 458800 & 757600 & 260 & 78 & 77 & 4.75 & 45 & 1.20 & 0.7 & 0.02 \\
\hline 19 & 458800 & 757800 & 200 & 80 & 81 & 4.80 & 46 & 1.10 & 0.6 & 0.01 \\
\hline 20 & 458800 & 758200 & 300 & 81 & 90 & 4.60 & 45 & 1.20 & 0.7 & 0.05 \\
\hline 21 & 458800 & 758400 & 300 & 35 & 27 & 1.69 & 25 & 1.10 & 1.2 & 0.03 \\
\hline 22 & 458800 & 758600 & 240 & 33 & 28 & 1.50 & 24 & 1.20 & 1.3 & 0.05 \\
\hline 23 & 458800 & 758800 & 400 & 27 & 25 & 1.20 & 21 & 1.10 & 1.4 & 0.06 \\
\hline
\end{tabular}




\begin{tabular}{|c|c|c|c|c|c|c|c|c|c|c|}
\hline 24 & 459000 & 757600 & 200 & 80 & 85 & 3.90 & 39 & 1.50 & 1.2 & 0.07 \\
\hline 25 & 459000 & 757800 & 280 & 85 & 90 & 3.95 & 41 & 1.30 & 1.1 & 0.04 \\
\hline 26 & 459000 & 758000 & 350 & 70 & 80 & 3.80 & 38 & 1.30 & 0.8 & 0.05 \\
\hline 27 & 459000 & 758200 & 560 & 50 & 60 & 2.50 & 25 & 1.20 & 0.9 & 0.04 \\
\hline 28 & 459000 & 758400 & 280 & 38 & 29 & 1.80 & 25 & 1.10 & 1.1 & 0.04 \\
\hline 29 & 459000 & 758600 & 270 & 40 & 30 & 1.60 & 28 & 1.10 & 1.2 & 0.03 \\
\hline 30 & 459200 & 757600 & 220 & 80 & 90 & 4.50 & 45 & 1.30 & 1.4 & 0.02 \\
\hline 31 & 459200 & 757800 & 230 & 85 & 98 & 4.60 & 42 & 1.10 & 1.1 & 0.08 \\
\hline 32 & 459200 & 758000 & 320 & 60 & 70 & 3.80 & 38 & 1.30 & 1.1 & 0.05 \\
\hline 33 & 459200 & 758200 & 540 & 45 & 55 & 2.60 & 31 & 1.10 & 0.8 & 0.04 \\
\hline 34 & 459200 & 758400 & 230 & 46 & 48 & 4.67 & 38 & 3.12 & 0.7 & 0.06 \\
\hline 35 & 459200 & 758600 & 230 & 47 & 50 & 4.70 & 33 & 3.50 & 0.6 & 0.04 \\
\hline 36 & 459400 & 757600 & 250 & 80 & 90 & 4.60 & 45 & 1.70 & 0.4 & 0.06 \\
\hline 37 & 459400 & 757800 & 160 & 85 & 98 & 4.50 & 47 & 1.20 & 0.5 & 0.06 \\
\hline 38 & 459400 & 758000 & 230 & 77 & 85 & 3.90 & 39 & 1.10 & 0.8 & 0.03 \\
\hline 39 & 459400 & 758200 & 300 & 60 & 70 & 3.80 & 35 & 1.20 & 0.7 & 0.04 \\
\hline 40 & 459400 & 758400 & 300 & 50 & 60 & 3.90 & 38 & 1.20 & 0.6 & 0.06 \\
\hline 41 & 459400 & 788600 & 200 & 44 & 46 & 4.19 & 35 & 1.10 & 0.8 & 0.05 \\
\hline 42 & 459600 & 757400 & 300 & 190 & 197 & 4.88 & 50 & 1.30 & 1.0 & 0.02 \\
\hline 43 & 459600 & 757600 & 250 & 180 & 170 & 4.70 & 45 & 1.70 & 1.1 & 0.02 \\
\hline 44 & 459600 & 757800 & 220 & 190 & 198 & 4.80 & 46 & 1.90 & 0.6 & 0.04 \\
\hline 45 & 459600 & 758000 & 250 & 100 & 130 & 4.50 & 38 & 1.70 & 0.5 & 0.08 \\
\hline 46 & 459800 & 757600 & 220 & 198 & 183 & 6.90 & 48 & 6.30 & 0.4 & 0.06 \\
\hline 47 & 459800 & 757800 & 230 & 190 & 180 & 6.70 & 45 & 5.80 & 0.3 & 0.04 \\
\hline 48 & 459800 & 758000 & 210 & 195 & 178 & 6.30 & 42 & 4.90 & 0.8 & 0.02 \\
\hline 49 & 459800 & 758200 & 230 & 100 & 110 & 5.80 & 41 & 4.70 & 0.7 & 0.06 \\
\hline 50 & 459800 & 758400 & 240 & 60 & 70 & 4.50 & 35 & 2.00 & 0.6 & 0.05 \\
\hline
\end{tabular}

Cr contents in the soils of Tikves are within the $25-98$ ppm interval (mean value of 90.62 ppm).

The highest chromium concentrations have been found near the villages of Sikovo and Rosoman (Fig. 3). A comparison between the results obtained for chromium concentrations in Tikves with those published for some countries in the world (5-215 ppm) (Naidenov et al. 1977, McKeague et al. 1980, Kitigashi et al. 1981, Ure et al. 1979) shows that chromium concentration in Tikves are similar to those found in other countries in the world. 


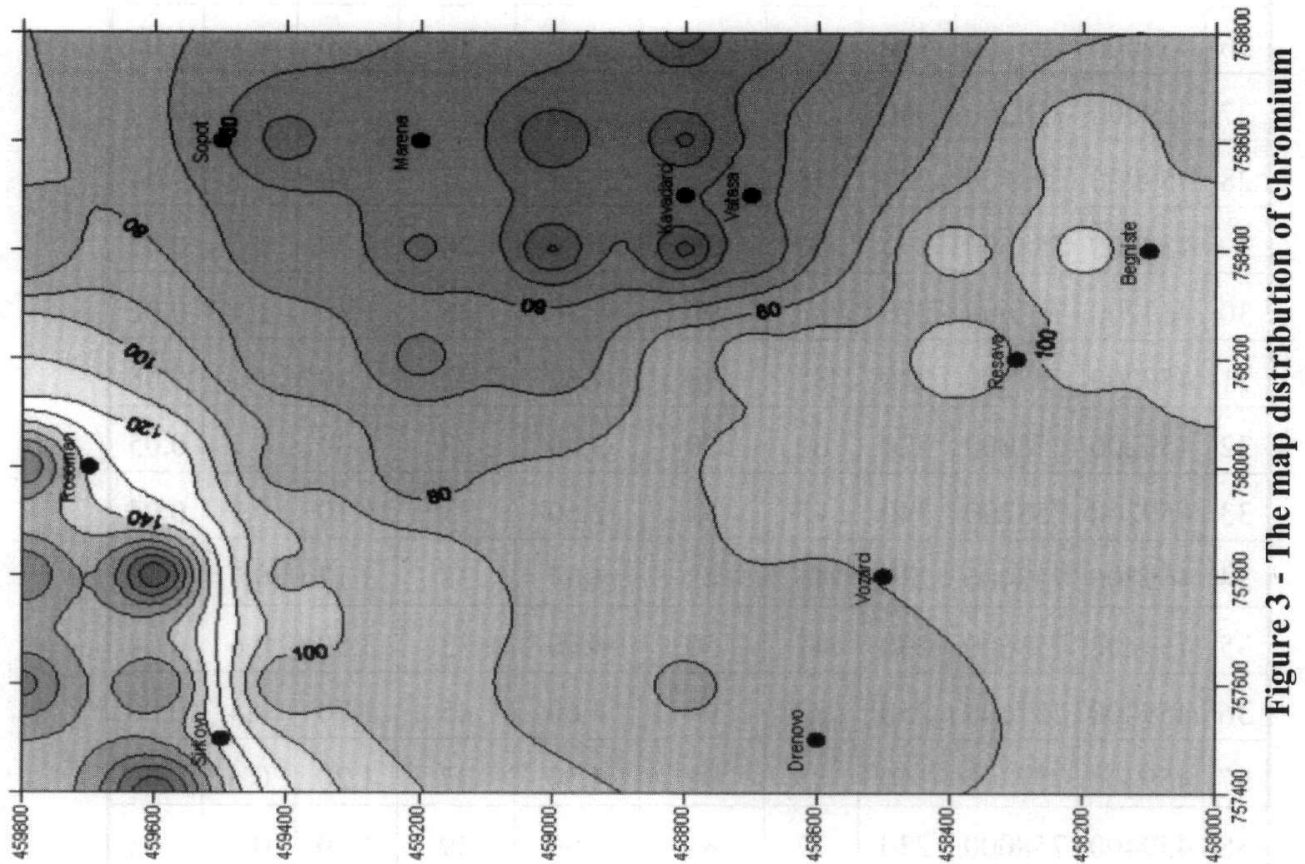

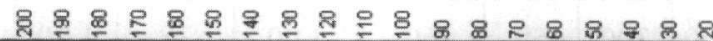

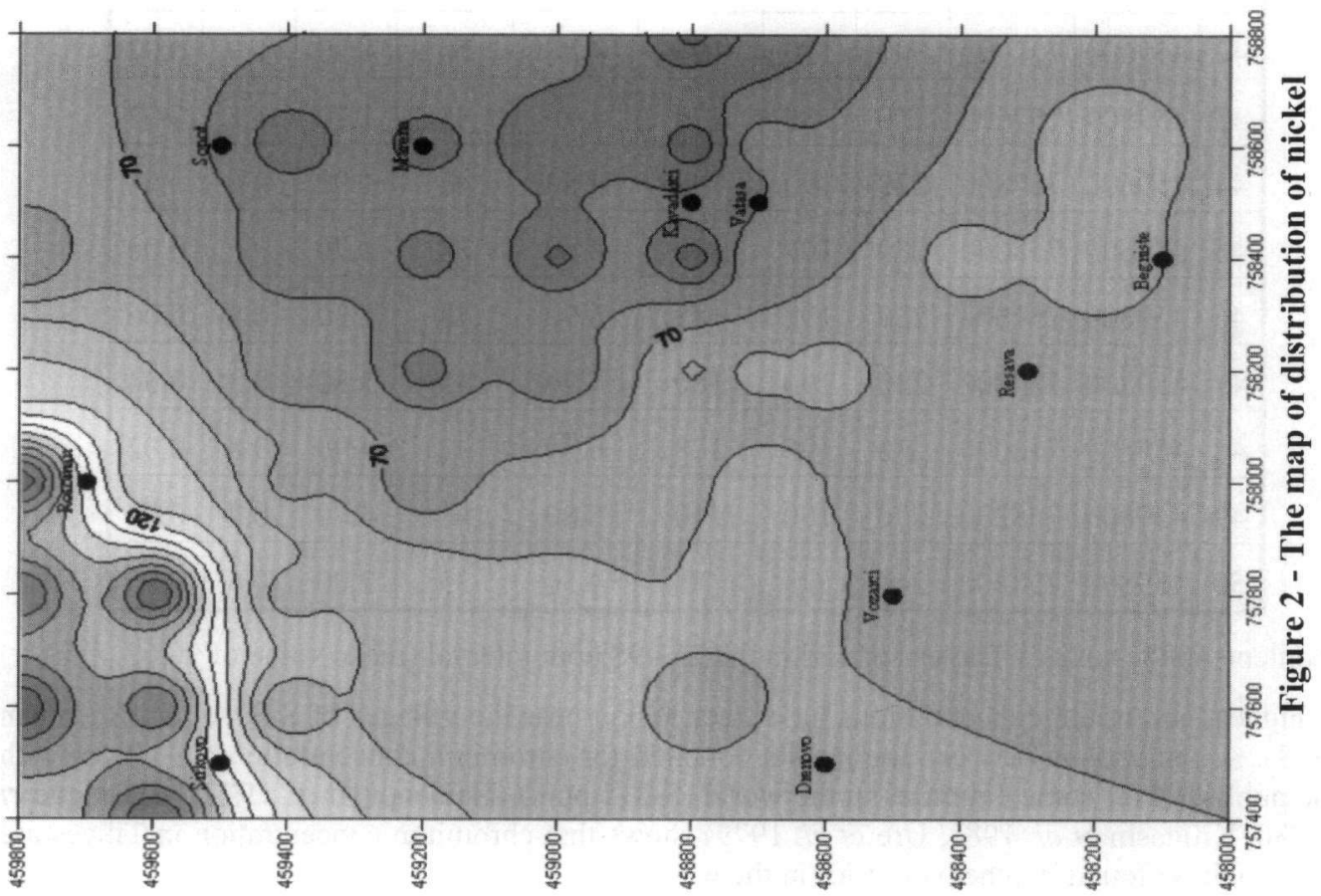




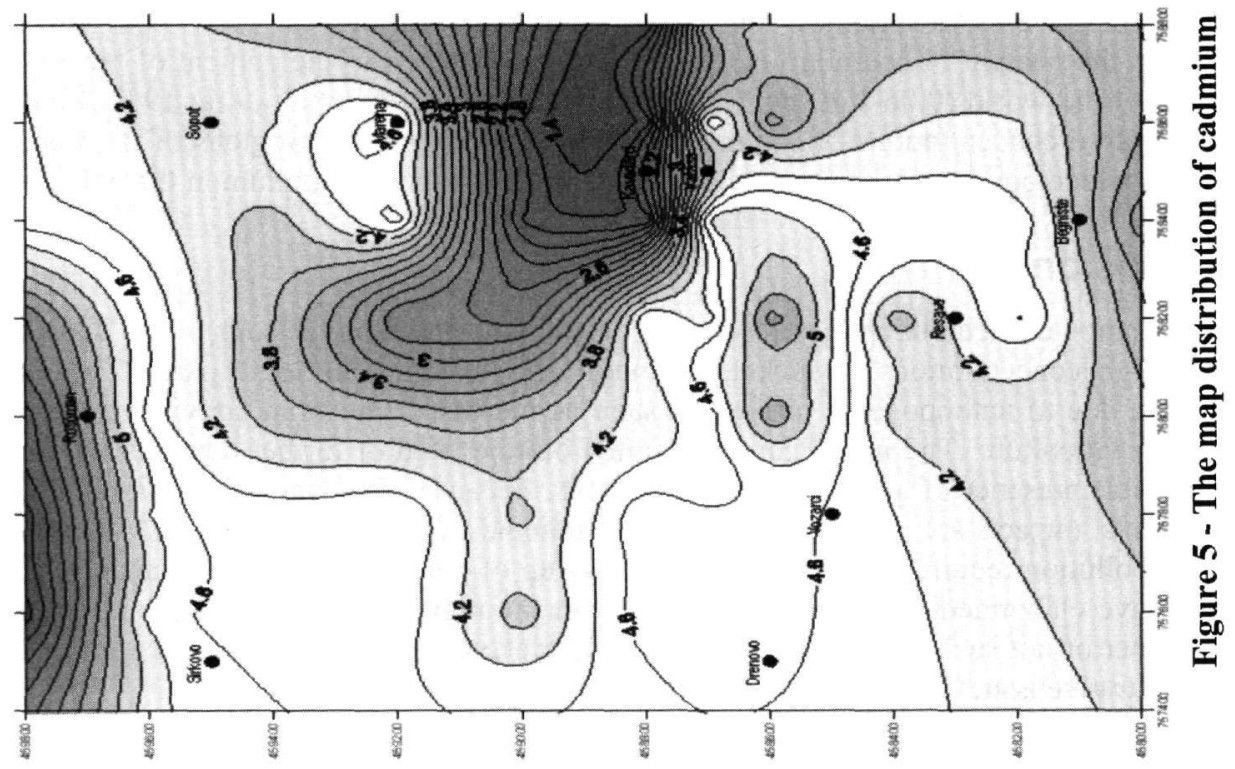

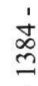

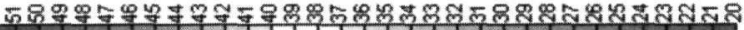

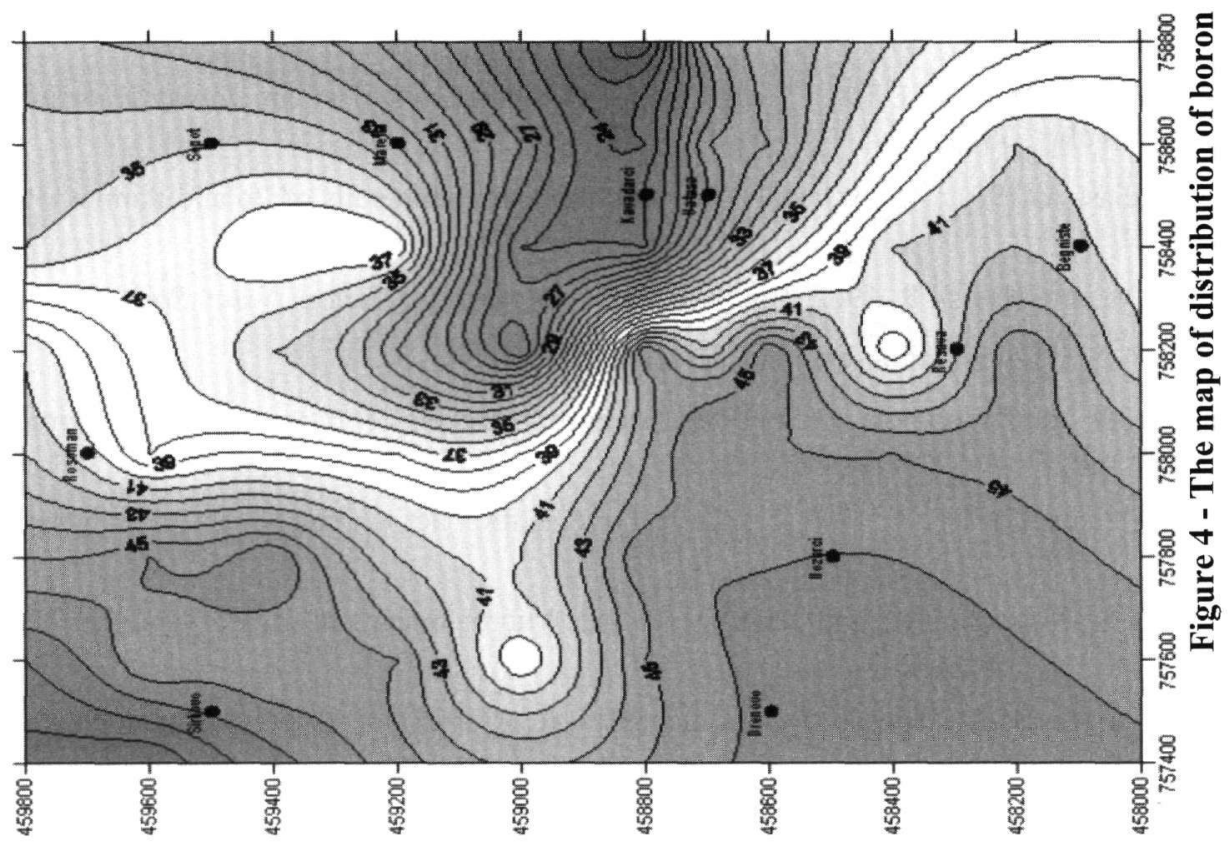


Content of B in the soils of the region under consideration is within the $21-47 \mathrm{ppm}$ interval or mean value of $38.72 \mathrm{ppm}$. The map of distribution shows that (Fig. 4) boron is almost evenly distributed. Boron concentrations in the soils of Tikves are similar to those in certain parts of the world (9-88 ppm) (Kosanovic et al. 1962, Ravikovic et al. 1961, Cumakov 1988).

The content of $\mathrm{Cd}$ in the area ranges from 1.20 to $6.90 \mathrm{ppm}$ or mean value of $3.5 \mathrm{ppm}$ (Fig. 5). It is obvious that the content of cadmium is relatively high compared to the content of the element in other parts of the world (0.06-1.10 ppm) (Kabata - Pendias 1981, Frank et al. 1979, Rauta et al. 1985). Increased concentrations of cadmium have been found in other regions of the Republic of Macedonia, which points out the possible anthopogenic emission of cadmium in the wider region.

\section{Conclusion}

The investigation carried out on the presence of $\mathrm{Se}, \mathrm{Ni}, \mathrm{Cd}, \mathrm{Bo}, \mathrm{Cr}$ in the soils of the Tikves region indicated high concentrations of nickel, cadmium and selenium in some parts. The increased amounts are due to anthopogenic influences such as increased industrial activity and the use of fertilizers in viticulture. The investigations pointed out the need of further detailed investigations for the possible presence of trace elements in the soils. Because of the variety of soil pollutants and concentrations, impacts are not very well known. Strategies to tackle the problems concerned with sources of pollution require prevention and cleaning up of polluted soils. Unfortunately, very few countries have elaborated legislation with respect to the registering and cleaning up of polluted soils. Whether or not such operations have been undertaken, polluted soils raise a number of legal and administrative issues.

\section{References}

Aubert, H., and Pinta, M, 1977. Trace Elements in Soils, Elsevier, Amsterdam, 395pp.

Bradley, R.I., 1980. Trace Elements in Soils Ground.

Cumakov, A, 1988. Trace Elements in Slovakian Soils and Plant Nutrition, PhD Thesis, Institut of Sugar Industry, Bratislava, 350pp.

Frank, R., Stonefield, K.I., and Sauda, P, 1979. Metals in agricultural soils of Ontario, Can. J. Soil Sci., 59, 99.

Kitagishi, K., and Yamane, I, 1981. Heavy metals Polution Soils of Japan, Japan Science Society, Press Tokiy, 302pp.

Kabata-Pendias, A, 1981. Heavy metals concentrations in arable soils of Poland Pamiet, Pilawski, $74,101$.

Kosanovic, V., and Halasi, R, 1962. Boron in soils of Voyvodina, Letop. Nauc. Radova , 6, 167.

Lag, J., 1974. Soil Selenium in relation to precipitation, Ambio, 3, 237.

McKeague, J.A., and Wolynetz, M.S., 1980. Beckground levels of minor elements in some Canadian soils, Geoderma, 24, 299.

Naidenov, M., and Travesi, A, 1977. Nondestructive neutron activation analysis of Bulgarian soils, Soil Sci., 124, 152.

Ravikovitch, S., Margolin, M., and Navroth, J, 1961. Microelements in soils of Israel, Soil Sci., 92, 85.

Rauta, C., Carstea, S., Mihailescu, A., and Lacatusu, R, 1985. Some aspectys of pedochemical and biogeochemical research in Romania, Proccedings of $1^{\text {st }}$ Symp. Of Geochemistry and Health, Ed. Iperial College, London, 236pp. 
Steines, E., 1980. Regional distribution of arsenic, selenium and antimony in humus layers of Norwegian soils, In Geomedical Aspects in Present and Future Research, Lag, J. Ed., Universitetforlaget, $217 \mathrm{p}$.

Tjell, J.Ch., and Hovmand, M.F, 1972. Metal concentration in Danish arable soils, Acta Agric. Scand., 28, 81 .

Ure, A.M., Bacon, J.R., Berrow, M.L., and Watt, J.J, 1979. The total trace elements content of some Scottish soils by spark source mass spectrometry, Geoderma, 22, 1-23. 